ARTIGO

ARTICLE

\section{Prevalência da doença de Chagas entre doadores de sangue do Estado do Piauí, Brasil, no período de 2004 a 2013}

\author{
Prevalence of Chagas disease among blood \\ donors in Piauí State, Brazil, from 2004 to 2013 \\ Prevalencia de la enfermedad de Chagas entre \\ donadores de sangre del estado de Piauí, Brasil, \\ durante el período de 2004 a 2013
}

Melissa Palis Santana 1

Reinaldo Souza-Santos 2

Andréa Sobral de Almeida 2

doi: 10.1590/0102-311X00123716

\section{Resumo}

Apesar do declínio na prevalência da doença de Chagas no Brasil, a Região Nordeste apresenta condições propicias ao seu recrudescimento. O objetivo deste estudo foi analisar a positividade por doença de Chagas entre doadores de sangue do Piaui entre 2004 e 2013. A prevalência de sorologia reagente para doenças de Chagas na triagem de doadores foi de 1\%, variando de 0,4\% na Regional de Saúde de Uruçuí a 2,4\% na Regional de Saúde de São Raimundo Nonato. Dos 220 municipios, 58,6\% apresentaram casos. Apenas 34,5\% das amostras positivas na triagem foram encaminhadas para testes complementares e entre estes, 84,4\% apresentaram resultados negativos. Nossos resultados indicam a possibilidade da manutenção da transmissão vetorial em áreas do Estado do Piauí e a necessidade da implantação de ações que melhorem o indice de realização dos testes complementares referentes aos casos positivos na triagem.

Doadores de Sangue; Seleção do Doador; Doença de Chagas

\section{Correspondência}

M. P. Santana

Centro de Hematologia e Hemoterapia do Piauí. Rua Primeiro de Maio 235, Teresina, PI 64001-430, Brasil. melissapalis@gmail.com

1 Centro de Hematologia e Hemoterapia do Piauí, Teresina, Brasil.

2 Escola Nacional de Saúde Pública Sergio Arouca, Fundação Oswaldo Cruz, Rio de Janeiro, Brasil. 


\section{Introdução}

Mesmo diante da redução da prevalência da doença de Chagas em todo o território brasileiro, em decorrência da eliminação do seu principal vetor, o Triatoma infestans, e do controle da transmissão transfusional (segunda via de transmissão em ordem de importância, depois da vetorial), a situação na Região Nordeste brasileira ainda é preocupante, principalmente por três motivos: concentra a maior quantidade de vetores secundários implicados na transmissão da doença, de especial importância o Triatoma brasiliensis, cujos hábitos peridomiciliares dificultam a sua localização, captura e controle químico por inseticidas; a região mantém altos índices de más condições de moradia, apropriados à colonização pelo triatomíneo; as medidas de fiscalização e controle entomológico não têm sido eficazes 1,2 .

Nos últimos anos foram desenvolvidos estudos de base populacional que evidenciaram a ocorrência da endemia em diversos estados brasileiros e, principalmente, no Piauí 2,3,4. O último inquérito sorológico realizado nesse estado, em 2002, entre pessoas residentes na zona rural, mostrou prevalências que chegaram a 11,6\% de sororreatividade em algumas localidades, valor superior ao dobro dos valores estimados para o estado em inquérito nacional realizado 20 anos antes. Já em outros municípios, nenhum caso foi identificado, o que ratifica a distribuição irregular, em mosaicos, a que se referiam Dias et al. 1 em relação à doença de Chagas na Região Nordeste. Desde 2002, nenhum inquérito sorológico em maiores de cinco anos de idade no estado foi realizado e publicado, o que demonstra uma lacuna no conhecimento desta endemia nos últimos 15 anos.

Como indicadores da endemicidade chagásica numa região ou período, os estudos de prevalência da doença de Chagas entre doadores de sangue mostram-se bastante úteis e refletem a prevalência de casos na sua forma indeterminada, ou seja, clinicamente silenciosa, denunciada pela presença de anticorpos anti-Trypanosoma cruzi circulantes. A presença desses anticorpos, detectada na testagem sorológica obrigatória na triagem de doadores, torna este doador inelegível para doações posteriores e desencadeia o descarte da bolsa de sangue coletada. Para o esclarecimento da situação clínica do doador, testes complementares são necessários na confirmação do diagnóstico, e ele deve ser encaminhado à orientação e avaliação médica 5,6.

Diante desse contexto, este trabalho objetiva analisar a positividade por doença de Chagas entre doadores de sangue do Estado do Piauí.

\section{Metodologia}

Trata-se de um estudo descritivo pautado em dados secundários e técnicas de geoprocessamento. Foram analisadas a prevalência de sorologia reagente para a doença de Chagas na triagem de doadores de sangue e a proporção de casos confirmados/inconclusivos entre aqueles submetidos à testagem complementar de residentes do Estado do Piauí, entre 2004 e 2013.

O termo "doadores de sangue" refere-se aos indivíduos que tiveram seu sangue coletado para armazenamento em serviço de hemoterapia (concomitantemente à coleta de amostras de sangue para os testes sorológicos obrigatórios), com a finalidade de transfusão sanguínea, sendo considerados "doadores inaptos sorológicos" aqueles que apresentaram resultados reagentes em quaisquer destes testes na triagem sorológica 7. A população deste estudo é constituída por todos os doadores de sangue residentes no Piauí, que efetuaram sua doação no hemocentro estadual (HEMOPI) entre janeiro de 2004 e dezembro de 2013.

Ressalta-se que a produção e distribuição de hemocomponentes para a transfusão no Estado do Piauí é exclusivamente pública e realizada, unicamente, pelo HEMOPI, que compreende o hemocentro coordenador, situado na capital Teresina, três hemonúcleos, situados nas principais cidades do interior do estado (Parnaíba, Picos e Floriano) e 21 agências transfusionais, distribuídas por todo o território estadual 6 .

O Piauí tem como estados limítrofes, Ceará, Pernambuco, Bahia, Tocantins e o Maranhão. As vegetações predominantes são: a caatinga, o cerrado, a mata de cocais e a floresta tropical. O clima é o tropical quente e úmido, na maior parte do território, e semiárido quente, nas regiões sudeste e centro-sul. Divide-se em 224 municípios, ocupando uma área de $251.611 .934 \mathrm{~km}^{2}$, com população de 
3.118.360 habitantes, estando 66\% destes em áreas urbanas e 34\% em rurais, com a população rural em aparente declínio (no Censo Demográfico de 2000, 37\% estavam na zona rural). É um estado pouco populoso, de municípios pequenos (73\% deles têm menos de 10 mil habitantes e $89 \%$ menos de 20 mil) e baixo Índice de Desenvolvimento Humano, o 24o do Brasil (http://www.ibge.gov.br, acessado em Out/2016).

Em 2007, o Piauí foi dividido em 11 territórios, denominados "territórios de desenvolvimento" 6, de acordo com as características ambientais, vocações produtivas, relações socioeconômicas e culturais estabelecidas entre as cidades.

A Secretaria de Saúde do Estado, apoiando-se na territorialização, instituiu 11 Regionais de Saúde (RS), cujas coordenações estão localizadas nos municípios-sede dos territórios de desenvolvimento, para fortalecer a descentralização das ações da política estadual de saúde nos municípios da área de abrangência do território 6 (Figura 1).

Utilizou-se duas fontes de dados relativas aos doadores, o Sistema de Gerenciamento em Serviços de Hemoterapia (HEMOVIDA) e o Gerenciador de Ambiente Laboratorial (GAL). O HEMOVIDA é um sistema informatizado desenvolvido pelo Departamento de Informática do SUS (DATASUS), em parceria com a Coordenação Geral de Sangue e Hemoderivados, utilizado pela hemorrede estadual do Piauí e pela maioria das hemorredes públicas brasileiras, específico para o gerenciamento de todas as etapas do ciclo do sangue 6,8 .

Os resultados dos testes complementares realizados pelo Laboratório Central de Saúde Pública do Piauí (LACEN-PI), entre 2004 e 2009, também foram registrados no HEMOVIDA. A partir de 2010, com a implantação do sistema informatizado GAL no LACEN-PI, os resultados dos testes complementares de doadores passaram a ser nele registrados.

Foram utilizadas as seguintes variáveis: doadores positivos ou reagentes para a doença de Chagas na triagem sorológica; casos confirmados (doadores reagentes na triagem e reagentes em pelo menos um dos testes complementares: imunofluorescência indireta (IFI), hemaglutinação indireta (HAI) ou ELISA de marca diferente do usado na triagem); casos inconclusivos (doadores reagentes no teste de triagem e não-reagentes ou indeterminados nos testes complementares); doadores negativos ou não-reagentes no teste de triagem; escolaridade; sexo; taxa de urbanização do município de residência; tipo de doador (categorias "doador de primeira vez" e "doador de retorno". Para cada ano do período 20042013, o doador foi classificado como "de primeira vez" caso a sua primeira doação tivesse ocorrido no ano em questão, e como "de retorno" caso já tivesse efetuado uma ou mais doações em anos anteriores).

Para o ano de nascimento foram criadas as categorias "até 1960", “1961-1970”, "1971-1980", “1981-1990”, “após 1990”. Optou-se pelo ano de nascimento e não pela idade porque estudos anteriores mostram que a prevalência da doença de Chagas foi diminuindo no Brasil ao longo das décadas do século passado em função das ações de controle da transmissão vetorial, que foram intensificadas a partir das décadas de 1980-1990. Dessa maneira, pode-se usar o ano de nascimento como um marcador de exposição à transmissão vetorial, e analisar a sua associação com a sororreatividade para doença de Chagas. A idade dos doadores de sangue pode se estender de 16 a 70 anos incompletos no período estudado.

As taxas de urbanização dos municípios foram agrupadas nas categorias “ $\leq 50 \%$ ”, “50 --| 70\%”, “70 --| 90\%”, “> 90\%”, no intuito de avaliar, por aproximação, a associação da prevalência de doadores soropositivos e a residência em área urbana ou rural, já que esta informação não pode ser obtida de forma direta nas fontes de dados utilizadas. Para o cálculo da taxa (população urbana x 100/população total), as populações total e urbana de cada município foram obtidas nos dados censitários do Instituto Brasileiro de Geografia e Estatística (IBGE) de 2000 e 2010, sendo calculado o incremento médio anual das populações entre 2004 e 2013, por meio da taxa média geométrica de crescimento anual (http://www.ibge.gov.br, acessado em Jan/2015).

Elaborou-se um banco de dados tendo como base os códigos de identificação dos indivíduos que efetuaram doações de sangue no período. Os doadores foram listados apenas uma vez, pois doadores não-reagentes na triagem sorológica podem doar até quatro vezes por ano.

Quando a análise referiu-se a períodos maiores que o anual, triênios e período de 10 anos, os doadores não-reagentes de retorno, listados em mais de um ano, foram contados apenas uma vez no período analisado. Desse modo garantiu-se, para o cálculo das prevalências, o exato número de doadores por período analisado (e não de doações) no denominador da frequência. 


\section{Figura 1}

Divisão do Estado do Piauí, Brasil, por Regionais de Saúde (RS)
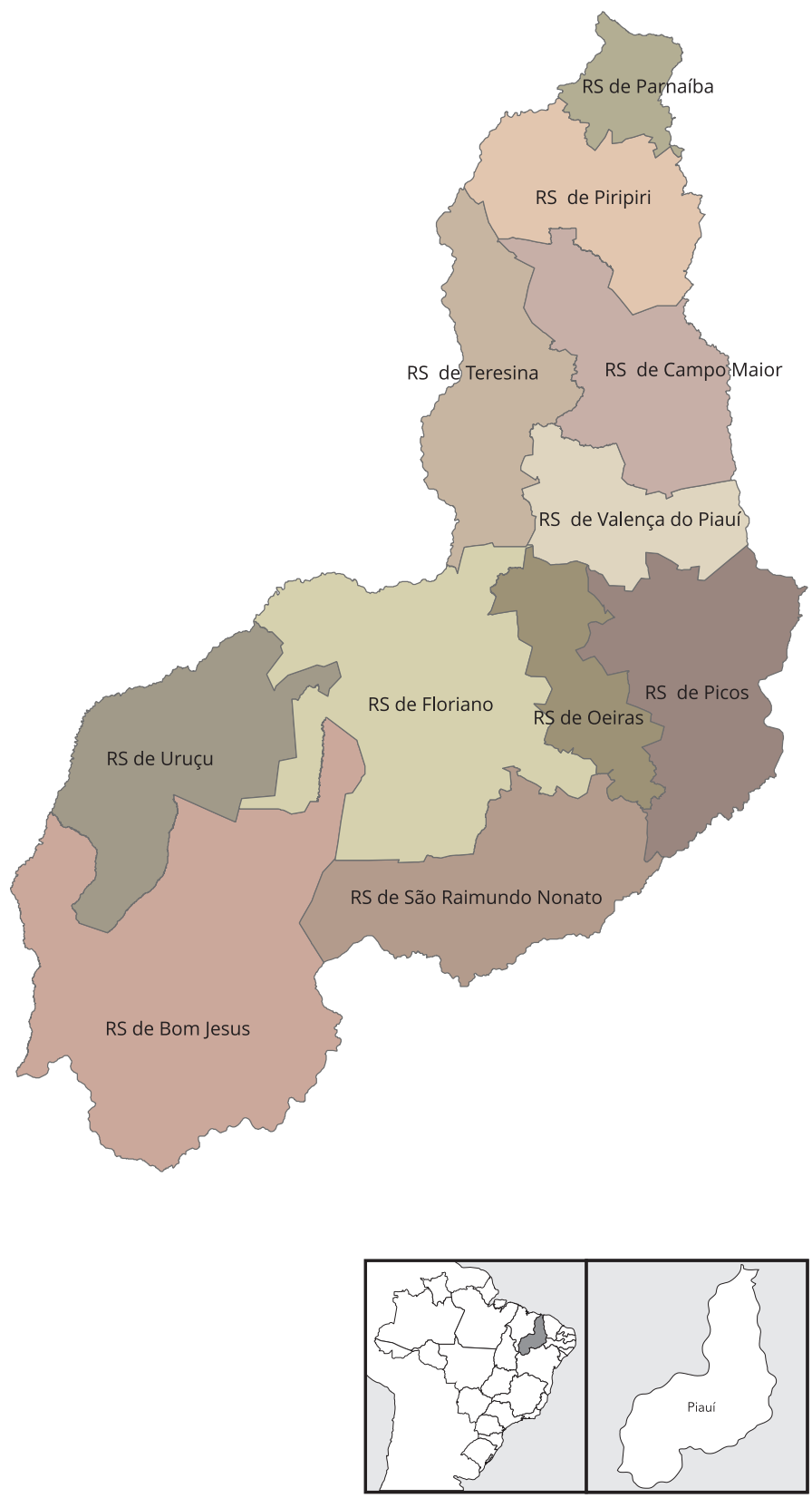

Foram calculadas: (a) prevalência de doadores de sangue com sorologia reagente para doença de Chagas no Estado do Piauí, anualmente, de 2004 a 2013, que foi realizada usando-se o número de doadores de sangue com sorologia reagente na triagem em relação ao total de doadores por ano; (b) prevalência de doadores no estado e período, segundo sexo, ano de nascimento, escolaridade taxa de urbanização do município de residência e tipo de doador; (c) prevalência de doadores nos períodos 2004-2013, 2004-2006, 2007-2009 e 2010-2013, por município e por RS, que foi realizada 
utilizando-se o número de doadores de sangue com sorologia reagente na triagem em relação ao total de doadores do período, por município e por RS; (d) proporção de casos inconclusivos e confirmados entre os doadores reagentes para doença de Chagas com amostras encaminhadas para testagem complementar; (e) prevalência de doadores de sangue com sorologia reagente por município considerando as seguintes faixas: 0,0; de 0,1 a 5,0; de 5,1 a 10; e $\geq 10,1$.

Para verificar se havia algum padrão espacial da distribuição da doença nas RS, foram elaborados mapas da prevalência sorológica na triagem nos triênios 2004-2006, 2007-2009 e 2010-2013; e do percentual de amostras encaminhadas para confirmação e de casos confirmados no período 20042013. Foram incluídas as localizações do Hemocentro e dos Hemonúcleos.

A malha digital das RS foi gerada por meio de operação geográfica, no caso agregação, com base na malha digital dos municípios do Piauí (http://www.ibge.gov.br), utilizando-se o programa TerraView 4.2.2 (Instituto Nacional de Pesquisas Espaciais; http://www.dpi.inpe.br/terraview). As análises foram efetuadas no programa IBM SPSS Statistics 20 (IBM Corp., Armonk, Estados Unidos). Foram usados os testes não paramétricos $\chi^{2} \mathrm{e}$ binomial.

A pesquisa foi aprovada pelo Comitê de Ética em Pesquisa da Escola Nacional de Saúde Pública Sergio Arouca/Fiocruz em 19/02/15 (CAAE: 38600114.7.0000.5240).

\section{Resultados}

De 1 de janeiro de 2004 a 31 de dezembro de 2013, 170.148 pessoas residentes no Piauí efetuaram uma ou mais doações de sangue no estado, sendo deste total, $107.895(63,4 \%)$ residentes na capital Teresina e 62.253 (36,6\%) residentes nos demais municípios. Dos 224 municípios do Piauí, 220 $(98,2 \%)$ estão representados neste trabalho. Apesar da maioria dos municípios ser pouco populosa, mais da metade deles contribuiu com pelo menos $1 \%$ da sua população, no período em estudo, como doadora de sangue.

O número de pessoas que efetivaram pelo menos uma doação de sangue aumentou progressivamente entre os anos de 2004 e 2013, de 23.828 pessoas em 2004 a 38.510 em 2013. Considerando todo o período, na RS de Teresina encontra-se o maior número de doadores (117.682). Nas demais regionais, variou de 476, RS de Uruçuí, a 15.179 doadores, RS de Parnaíba (Tabela 1).

Quanto às prevalências de reatividade na triagem dos doadores de sangue por ano de ocorrência, nota-se menor valor nos anos de 2009 e 2010 (0,2\%), e o maior valor no ano de 2013 (1,1\%); no período de 10 anos analisados, a prevalência foi de 1,0\% (Tabela 1).

Todos os 170.148 doadores de sangue do período estudado foram inicialmente testados no serviço de hemoterapia por exame sorológico de metodologia ELISA para a detecção de anticorpos anti-Tr. cruzi.

Dos 220 municípios do Piauí representados no estudo atual, 129 (58,6\%) apresentaram doadores com sorologia reagente, sendo 105 municípios $(48,6 \%)$ na faixa de prevalência entre 0,1 e 5,0; 20 municípios $(9,3 \%)$ entre 5,1 e 10,0; e $6(2,8 \%) \geq 10,1$. Do total, 85 municípios $(39,3 \%)$ não registraram doadores reagentes.

Observamos que os municípios com prevalências mais altas foram Morro Cabeça no Tempo (28,6\%), Santa Filomena (14,7\%), Sebastião Barros (14,3\%), Bonfim do Piaú (14,3\%), Pavussu (11,8\%) e Caracol $(11,1 \%)$. Os três primeiros citados estão localizados na RS de Bom Jesus, no extremo sul do estado, região dos cerrados. Os mais populosos municípios do estado (Teresina, Parnaíba, Picos, Piripiri, Floriano, Campo Maior) apresentaram prevalências que variaram de 0,3\% em Piripiri a 1,3\% em Picos, sendo a prevalência na capital de 1,1\%.

Quanto à análise da distribuição geográfica da prevalência considerando o período de 10 anos (2004-2013), observa-se a maior prevalência (2,01 a 2,4\%) na RS de São Raimundo Nonato, a menor na RS de Uruçuí (0,42\%), e prevalência de 1,01-2\% na maioria das demais RS, com exceção para as RS de Campo Maior, Piripiri e Parnaíba, com 0,421-1\%. Já a análise pelos três períodos do estudo, 2004-2006, 2007-2009 e 2010-2013, permitiu verificar que nas RS de Parnaíba, Piripiri, Campo Maior e Teresina a prevalência manteve-se na mesma faixa $(0,01-1 \%)$ em todos os períodos analisados. As RS de Picos, Floriano e Valença do Piauí, inicialmente também com prevalência de 0,01-1\%, aumentaram para 1,01-2\% a partir do segundo (RS de Picos) e do terceiro períodos (RS de Valença e Floriano) (Figura 2). 
Ocorrência de doadores com teste de triagem sorológica reagente para doença de Chagas por Regional de Saúde e ano de doação. Estado do Piauí, Brasil, 2004-2013.

\begin{tabular}{|c|c|c|c|}
\hline & \multirow[t]{2}{*}{ Doadores } & \multicolumn{2}{|c|}{ Reagentes } \\
\hline & & $\mathbf{n}$ & $\%$ \\
\hline \multicolumn{4}{|l|}{ Regional de Saúde } \\
\hline Parnaíba & 15.178 & 102 & 0,70 \\
\hline Piripiri & 8.866 & 44 & 0,50 \\
\hline Campo Maior & 4.956 & 47 & 0,90 \\
\hline Teresina & 117.682 & 1.218 & 1,00 \\
\hline Valença do Piauí & 1.716 & 22 & 1,30 \\
\hline Picos & 9.179 & 126 & 1,40 \\
\hline Oeiras & 2.094 & 41 & 2,00 \\
\hline Floriano & 7.956 & 87 & 1,10 \\
\hline São Raimundo Nonato & 1.004 & 24 & 2,40 \\
\hline Uruçuí & 476 & 2 & 0,40 \\
\hline Bom Jesus & 1.041 & 18 & 1,70 \\
\hline Total & 170.148 & 1.730 & 1,00 \\
\hline \multicolumn{4}{|l|}{ Ano de doação } \\
\hline 2004 & 23.828 & 198 & 0,83 \\
\hline 2005 & 28.841 & 110 & 0,38 \\
\hline 2006 & 29.889 & 91 & 0,30 \\
\hline 2007 & 31.646 & 352 & 1,11 \\
\hline 2008 & 30.005 & 115 & 0,38 \\
\hline 2009 & 32.921 & 65 & 0,18 \\
\hline 2010 & 30.776 & 55 & 0,18 \\
\hline 2011 & 34.479 & 129 & 0,37 \\
\hline 2012 & 36.075 & 172 & 0,48 \\
\hline 2013 & 38.510 & 443 & 1,15 \\
\hline Total & 170.148 * & 1.730 & 1,02 \\
\hline
\end{tabular}

* O número total de doadores no período de 2004-2013 não corresponde à soma dos valores de cada ano porque um mesmo doador pode ter doado em dois ou mais anos do período. Na avaliação de cada ano e do período 2004-2013 cada doador é contado apenas uma vez.

As RS de São Raimundo Nonato, Oeiras e Uruçuí apresentaram declínio na prevalência. As RS de São Raimundo Nonato e de Oeiras, inicialmente com as maiores prevalências entre as RS (3,01-6\% em São Raimundo Nonato e 2,01-3\% em Oeiras), registraram declínio para 1,01-2\% a partir do segundo período. A RS de Uruçuí teve a prevalência diminuída de 1,01-2\% no primeiro período para 0,01-1\% no último, não havendo registro de reagentes entre 2007-2009 (Figura 2).

$\mathrm{Na}$ RS de Bom Jesus, o comportamento da prevalência foi flutuante: elevou de 1,01-2\% entre 2004-2006 para 2,01-3\% entre 2007-2009, caindo para faixa inferior à inicial (0,01-1\%) entre 2010 2013 (Figura 2).

Observa-se que entre 2004 e 2013, as RS de Picos, Floriano e Valença registraram aumento na prevalência da doença de Chagas entre doadores; as RS de Parnaíba, Piripiri, Campo Maior e Teresina mantiveram-se estáveis e as RS de São Raimundo Nonato, Oeiras, Uruçuí e Bom Jesus apresentaram declínio (Figura 2).

Quanto às características dos doadores, diferenças significativas ( $\mathrm{p}<0,001)$ entre positivos e negativos foram encontradas em relação ao sexo, ano de nascimento e escolaridade, com maiores percentuais para o sexo masculino, nascidos entre 1981 e 1990, "sem instrução ou fundamental incompleto" e "médio completo”. A comparação estatística entre os principais estratos de cada variável confirmou 


\section{Figura 2}

Distribuição da prevalência (\%) de sorologia reagente para doença de Chagas na triagem de doadores de sangue do Estado do Piauí, Brasil, segundo Regionais de Saúde, nos períodos 2004-2006, 2007-2009, 2010-2013.

2a) $2004-2006$

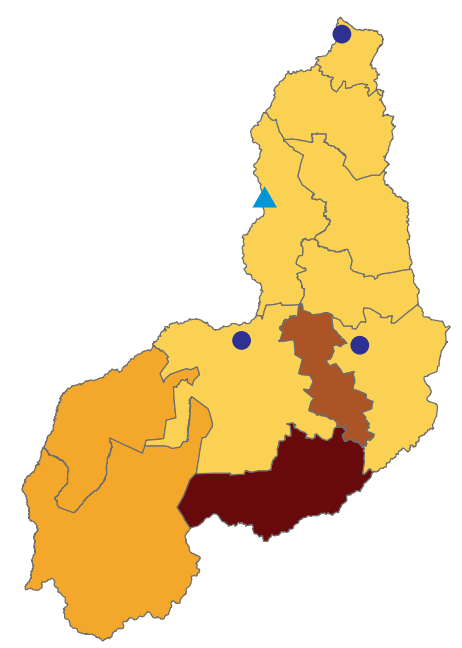

2b) $2007-2009$

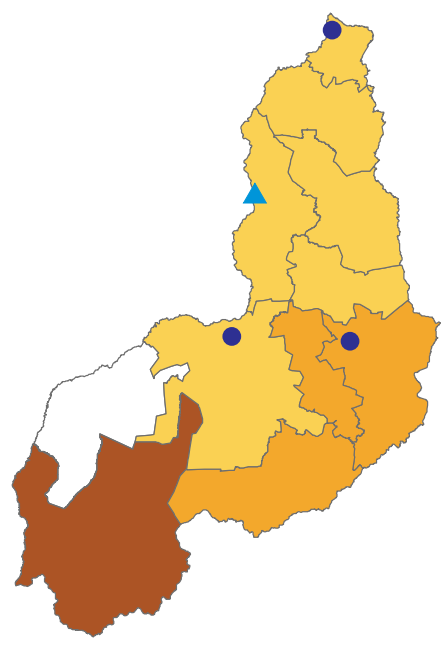

2c) $2010-2013$

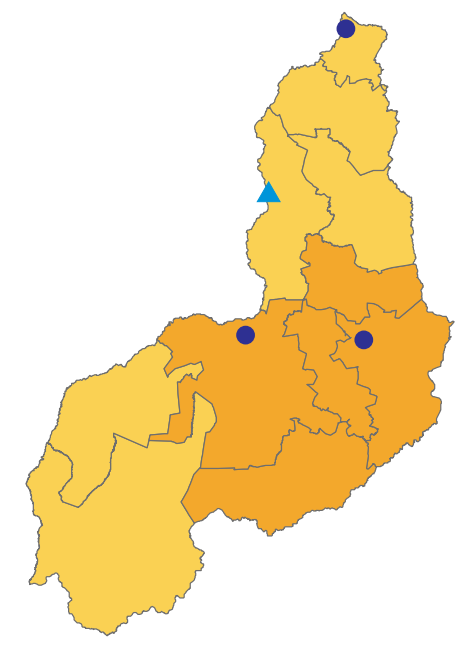

- Hemonúcleo regional (Picos, Parnaíba e Floriano)

- Hemocentro coordenador (Teresina)

Prevalência na triagem

$\square, 0,00$

$0,01-1,00$

$1,01-2,00$

$2,01-3,00$

$3,01-6,00$

0

$137.5 \quad 275$

550

$825 \mathrm{~km}$

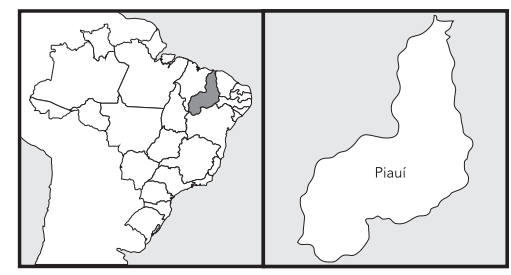

as diferenças estatísticas encontradas. As maiores prevalências foram identificadas nos indivíduos do sexo masculino (1,13\%), nascidos até 1960 (1,62\%), sem instrução (1,26\%), residentes em municípios com taxa de urbanização $\leq 50 \%(1,18 \%)$ e sendo doador de retorno $(1,06 \%)$ (Tabela 2$)$. 


\section{Tabela 2}

Prevalência de doença de Chagas na triagem de doadores de sangue segundo características sociodemográficas e tipo de doador. Estado do Piauí, Brasil, 2004-2013.

\begin{tabular}{|c|c|c|c|c|c|}
\hline \multirow[t]{2}{*}{ Características } & \multicolumn{2}{|c|}{ Positivo } & \multicolumn{2}{|c|}{ Negativo } & \multirow[t]{2}{*}{ Prevalência } \\
\hline & $\mathbf{n}$ & $\%$ & $\mathbf{n}$ & $\%$ & \\
\hline \multicolumn{6}{|l|}{ Sexo * } \\
\hline Masculino & 1.194 & 69,0 & 104.446 & 62,0 & 1,13 \\
\hline Feminino & 536 & 31,0 & 63.971 & 38,0 & 0,83 \\
\hline Total & 1.730 & 100,0 & 168.417 & 100,0 & \\
\hline \multicolumn{6}{|l|}{ Ano de nascimento * } \\
\hline Até 1960 & 261 & 15,1 & 15.850 & 9,4 & 1,62 \\
\hline $1961-1970$ & 315 & 18,3 & 27.907 & 16,6 & 1,12 \\
\hline $1971-1980$ & 435 & 25,2 & 46.427 & 27,6 & 0,93 \\
\hline $1981-1990$ & 523 & 30,3 & 62.613 & 37,3 & 0,83 \\
\hline Após 1991 & 190 & 11,0 & 15.259 & 9,1 & 1,23 \\
\hline Total & 1.724 & 100,0 & 168.056 & 100,0 & \\
\hline \multicolumn{6}{|l|}{ Escolaridade * } \\
\hline Sem instrução ou Fundamental incompleto & 549 & 31,9 & 43.110 & 25,8 & 1,26 \\
\hline Fundamental completo & 313 & 18,2 & 30.341 & 18,2 & 1,02 \\
\hline Médio completo & 754 & 43,9 & 80.223 & 48,0 & 0,93 \\
\hline Superior completo & 103 & 6,0 & 13.478 & 8,0 & 0,76 \\
\hline Total & 1.719 & 100,0 & 167.152 & 100,0 & \\
\hline \multicolumn{6}{|l|}{ Taxa de urbanização do município de residência } \\
\hline$\leq 50 \%$ & 156 & 9,0 & 13.048 & 7,7 & 1,18 \\
\hline $50--\mid 70 \%$ & 141 & 8,2 & 15.006 & 8,9 & 0,93 \\
\hline $70--\mid 90 \%$ & 208 & 12,0 & 20.657 & 12,3 & 1,00 \\
\hline$>90 \%$ & 1.225 & 70,8 & 119.707 & 71,1 & 1,01 \\
\hline Total & 1.730 & 100,0 & 168.418 & 100,0 & \\
\hline \multicolumn{6}{|l|}{ Tipo de doador } \\
\hline Primeira vez & 906 & 52,4 & 91.207 & 54,2 & 0,98 \\
\hline Retorno & 824 & 47,6 & 77.211 & 45,8 & 1,06 \\
\hline Total & 1.730 & 100,0 & 168.418 & 100,0 & \\
\hline
\end{tabular}

* Variáveis com diferenças estatísticas significantes; $p \leq 0,05$.

Quanto à confirmação dos casos positivos na triagem, em todo o período do estudo, das 1.730 amostras reagentes na triagem pelo ELISA, 597 (34,5\%) foram encaminhadas ao LACEN-PI para testagem complementar por IFI ou HAI ou ELISA (de marca distinta do empregado na triagem): 351 foram testadas apenas por IFI, 74 testadas apenas por HAI, 138 por IFI e HAI, 34 por IFI e ELISA. Entre as amostras encaminhadas para o teste complementar, $504(84,42 \%)$ resultados foram não-reagentes.

Em todos os anos do período houve amostras positivas encaminhadas para testagem complementar, exceto em 2011, com grande variação do percentual de encaminhamento, sendo quase nulo entre 2008 e 2010. Entre as 597 amostras encaminhadas, 270 (45,2\%) eram de doadores de primeira vez e 327 (54,8\%) de doadores de retorno.

Nenhuma das RS teve mais do que $40 \%$ das suas amostras reagentes para doença de Chagas encaminhadas para testagem complementar. Entre as RS, o percentual de encaminhamento variou de 0\% (RS de Uruçuí) a 39,2\% (RS de Teresina e Parnaíba). As três regionais com o maior percentual de encaminhamento abrigam unidades que coletam sangue e convocam doadores para retestagem: RS de Teresina (39,2\%), onde está o hemocentro coordenador, e as RS de Parnaíba (39,2\%) e de Floriano (32,2\%), onde estão dois hemonúcleos do estado. As RS de São Raimundo Nonato, Campo Maior e 
Oeiras tiveram 29,2\%, 25,5\% e 22\% de amostras encaminhadas, respectivamente. Nas demais RS, o encaminhamento foi de 10 a $20 \%$ das amostras (Figura 3).

Entre as amostras submetidas à testagem complementar de 2004-2013, 93 (15,6\%) apresentaram resultados reagentes (casos confirmados) e 504 (84,4\%) não-reagentes (casos inconclusivos). Os casos inconclusivos variaram de 50 a $100 \%$ ao longo dos anos.

Quanto à distribuição do percentual de casos confirmados por RS, o maior percentual foi registrado nas RS de Bom Jesus, São Raimundo Nonato, Picos, Oeiras e Valença, com confirmação de 40,01-100\% dos casos, seguidas da RS de Floriano, com confirmação de 20,01-40\% dos casos. As RS de Teresina, Piripiri, Campo Maior e Parnaíba apresentaram o menor percentual (10,01-20\%) de casos confirmados; a RS de Uruçuí não teve amostras encaminhadas para testagem complementar (Figura 3).

\section{Figura 3}

Distribuição percentual de amostras encaminhadas para testagem confirmatória e de casos confirmados, por Regional de Saúde. Estado do Piauí, Brasil, 2004-2013.

3a) Amostras para testagem confirmatória

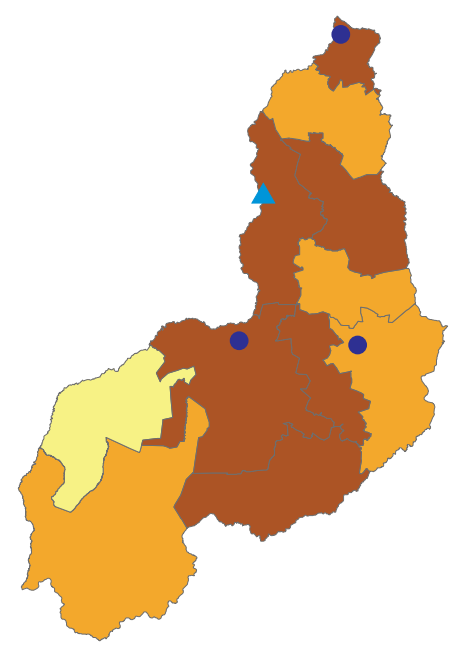

3b) Casos confirmados

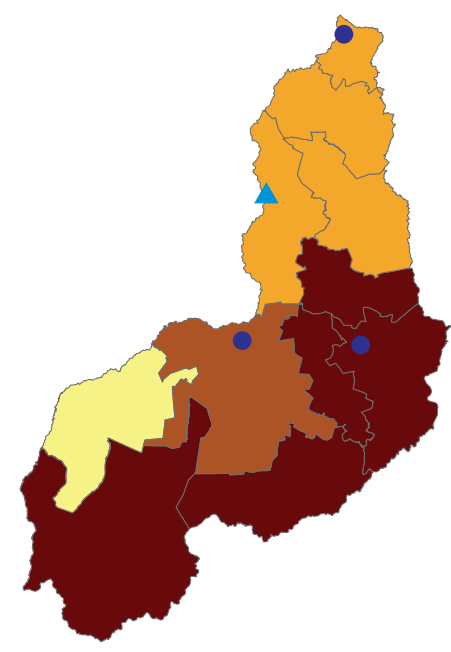

Hemonúcleo regional (Picos, Parnaíba e Floriano)

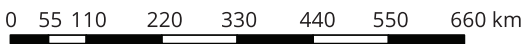

- Hemocentro coordenador (Teresina)

$\%$

0,00

$0,01-10,00$

$\square 10,01-20,00$

20,01-40,00

$40,01-100,00$

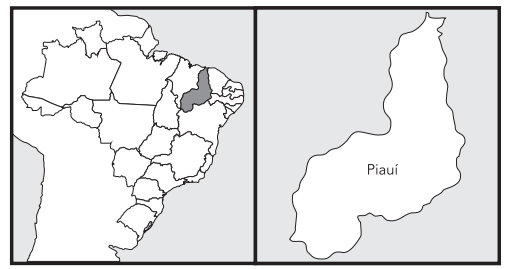




\section{Discussão}

Os resultados do trabalho evidenciaram que a prevalência de sorologia reagente para doença de Chagas na triagem de doadores de sangue do Piauí, no período de 10 anos analisado, foi de $1 \%$. Na literatura, poucos estudos analisaram a prevalência dessa doença utilizando como unidade de análise o doador, como o presente trabalho, e não as doações, e foram produzidos há mais de uma década 9,10, o que limita as comparações. Sobreira et al. 9 descreveram 1,9\% entre doadores do hemocentro de Iguatu (Ceará) em 1996-1997, e Soussumi 10, 2,5\% entre doadores de primeira vez em Ribeirão Preto (São Paulo), entre 1996-2001.

Os demais estudos referem-se à prevalência da doença entre doações, variando no Brasil entre 0,1 e $0,3 \%$, segundo os trabalhos mais recentes $11,12,13,14,15,16$. O relatório de produção hemoterápica brasileira, com dados de 2013, indica 0,34\% de doações reagentes para a doença de Chagas na triagem entre os doadores, com os maiores percentuais $(0,5 \%)$ no Nordeste e Sudeste ${ }^{17}$. Ressaltamos que a comparação das diferentes prevalências entre as regiões e serviços deve levar em conta, além da real magnitude da infecção na região geográfica correspondente, o tamanho da amostra, as técnicas sorológicas utilizadas e a metodologia empregada no estudo.

Como não existem publicações de trabalhos prévios sobre infecção por doença de Chagas entre doadores de sangue no Piauí, não foi possível análise comparativa nessa população. Entretanto, ao compararmos a prevalência encontrada neste estudo entre doadores - 1\%, e a prevalência descrita entre a população rural do estado no ano de 2002 - 1,9\% 3, observa-se valores próximos.

Em relação às características dos doadores, ao comparar o achado de maior prevalência entre o sexo masculino, observamos variação na literatura, dependendo da área e ano do estudo 9,13. Quanto à maior prevalência de indivíduos com data de nascimento anterior a 1960, semelhante ao identificado em outros estudos 9,11,13, pode estar relacionada às ações de controle vetorial, mais intensas a partir da década de 1980 3,11. Infelizmente, a segunda maior prevalência foi identificada entre os indivíduos com data de nascimento após 1991, necessitando investigações para compreender o que está ocorrendo. Maior prevalência entre sorologia reagente e baixa escolaridade também foi identificada em outros estudos 3,13,16, assim como entre aqueles que residem em municípios com menor taxa de urbanização 3,13,15, apesar de as diferenças não terem sido estatisticamente significantes, em relação à taxa de urbanização. Em estudos anteriores, também observou-se maior frequência de casos confirmados entre doadores de primeira vez 13,16, apesar de a maior prevalência encontrada ter sido entre os doadores de retorno e esta diferença não ter sido estatisticamente significante. Diferentemente das maiores prevalências aqui apresentadas, notamos maiores porcentuais de positivos nos estratos de nascimento entre 1981 e 1990 e entre indivíduos com escolaridade na categoria médio completo demandando cautela na interpretação dos resultados.

Segundo Borges-Pereira et al. 3, entre 216 municípios avaliados, havia pessoas soropositivas para doença de Chagas em 131 (60,6\%) deles. Observamos uma distribuição da frequência de municípios por faixas de prevalência muito semelhantes entre os dois estudos.

A análise da prevalência em um período longo, como a realizada neste trabalho, permitiu que as RS com municípios muito pouco populosos, e consequentemente com menor número de doadores, fossem melhor representadas, como Uruçuí (476 doadores), São Raimundo Nonato (1.004 doadores) e Bom Jesus (1.041). Além disso, observa-se maior número de doadores nas regionais onde existe município com estrutura física da hemorrede para a coleta de sangue - o hemocentro coordenador de Teresina e os hemonúcleos de Parnaíba, Floriano e Picos.

Mesmo observando variações entre as prevalências encontradas em relação às do trabalho de Borges-Pereira et al. 3 , não é possível afirmar que estas efetivamente aumentaram ou diminuíram, tendo em vista as limitações decorrentes da comparação entre estudos com populações diferentes e com metodologia de testagem sorológica diversa (IFI em 20023 e ELISA em 2004-2013, no estudo atual), mas chama a atenção o comportamento da prevalência nas RS de Valença e Teresina, com tendência contrária à observada nas demais.

É esperado que a prevalência entre doadores seja sempre menor em relação à da população em geral, pois trata-se de indivíduos previamente triados clinicamente e grande parte deles já triados sorologicamente também, no caso dos doadores de retorno 5. Portanto, o achado neste estudo de prevalências maiores na RS de Valença e de Teresina em relação ao trabalho de 2002 sugere um aumento do número 
de casos nos últimos anos. É importante enfatizar, entretanto, que esses resultados referem-se à sorologia reagente na triagem de doadores, realizada com metodologia ELISA, que pode não ter seu resultado reproduzido por outra metodologia, podendo não se tratar, em alguns casos, de infecção chagásica.

Quanto à distribuição geográfica, a RS de Uruçuí teve a prevalência diminuída de 1,01-2\% no primeiro período para 0,01-1\% no último. Nessa Regional, a ausência de casos registrados entre 20072009 (prevalência $=0 \%$ ) provavelmente deu-se por conta do baixo número de doações provenientes da região no período (68 doações).

Além disso, Borges-Pereira et al. 3 verificaram a estreita relação entre soroprevalência e a presença de triatomíneos nas áreas pesquisadas, em especial T. brasiliensis e Triatoma pseudomaculata, e a maior queda da soroprevalência, em relação ao inquérito realizado entre 1975-1980 18, nos municípios onde antes havia o T. infestans. Gurgel-Gonçalves et al. 4 confirmaram a ampla distribuição de T. brasiliensis e T. pseudomaculata no Piauí, principalmente nas áreas de caatinga, localização das RS de São Raimundo Nonato, Oeiras, Picos e Valença. Nesse contexto, estudos considerando doadores de sangue, que sugerem aumento da soroprevalência da doença de Chagas, deveriam servir de base para estudos adicionais sobre a distribuição e infecção dos vetores, reforçando a necessidade de direcionamento das ações de vigilância entomológica.

Os resultados evidenciaram baixo percentual de amostras reagentes encaminhadas para testagem complementar, além de uma heterogeneidade geográfica. Destacamos que o hemocentro coordenador centraliza o recebimento das amostras das doações de todo o estado para a execução dos testes de triagem sorológica, e a partir daí envia as amostras reagentes para testes complementares no LACEN-PI. Logo, esperava-se maior homogeneidade no percentual de encaminhamento entre as RS. É possível que parte das amostras encaminhadas para testagem complementar não tenha sido amostras da doação, mas amostras coletadas quando da convocação do doador reagente na triagem para retestagem e orientação. Quando chamados para retornar ao serviço de hemoterapia, parte dos doadores pode não comparecer, principalmente os residentes em localidades distantes dos hemonúcleos e hemocentro; ou quando do comparecimento, pode apresentar nova testagem ELISA negativa, o que torna dispensável o envio da amostra para testagem por outras metodologias. $\mathrm{O}$ resultado negativo nesse segundo momento pode significar um resultado falso-positivo na triagem sorológica da doação, possível quando se utiliza metodologia de alta sensibilidade e menor especificidade, como o ELISA. Outras causas de resultados falso-positivos são reações inespecíficas, como a contaminação cruzada entre amostras e amostras inadequadas. Além disso, parte dos indivíduos reagentes terá seu título de anticorpos diminuído ou deixará de apresentar anticorpos circulantes com o passar do tempo, mesmo na ausência de tratamento 19,20,21. Isso poderia justificar os casos em que o doador retorna para retestagem, com resultado não-reagente, meses ou anos após a testagem inicial reagente. De qualquer modo, sabe-se que todas as amostras encaminhadas para testagem complementar eram reagentes no ELISA empregado na triagem.

Os critérios utilizados pelo serviço para o encaminhamento das amostras não foram investigados, mas parecem não estar limitados à exigência legal que vigorou entre o final de 2011 e 2013 22, que determinava a confirmação apenas entre doadores de retorno, já que nem todos os 824 doadores de retorno reagentes na triagem foram investigados, mas apenas 327 (39,7\%).

Ainda que não seja obrigatória ao serviço de hemoterapia a confirmação do diagnóstico da doença, o possível não comparecimento do doador convocado revela que ele está deixando de receber orientações sobre a doença e deixando de ser encaminhado para o serviço médico de referência. O não comparecimento do doador, assim como a sorologia positiva em doadores de retorno devem ser obrigatoriamente comunicados à vigilância em saúde municipal e estadual, para que auxiliem na busca e investigação dos casos. Ressalta-se que a avaliação do cumprimento desse fluxo não foi objeto desta pesquisa.

Em relação à análise das diferenças anuais das proporções de casos confirmados/inconclusivos, identificou-se algumas limitações: não foi possível relacionar as marcas dos testes imunoenzimáticos (ELISA) a cada um dos doadores testados na triagem nos anos em que mais de uma marca foi utilizada, para que se comparasse o número de casos inconclusivos gerado por cada um deles e consequentemente a sua especificidade; os critérios usados pelo serviço para o encaminhamento de amostras reagentes para testagem complementar não foram investigados, e esta seleção pode ter relação com a confirmação de maior ou menor número de casos; entre os anos de 2008 e 2011, o número de amostras encaminhadas para testagem complementar foi quase nulo. 
Além disso, este estudo não teve como objetivo aferir a sensibilidade e especificidade dos testes sorológicos empregados na triagem dos doadores, nem avaliar os processos de trabalho do serviço de hemoterapia, mas conhecer a proporção de casos inconclusivos no período estudado, tendo em vista o seu impacto no próprio serviço e na vida do doador.

Não existe um teste padrão-ouro no diagnóstico de doença de Chagas. O Ministério da Saúde 23 preconiza, para o diagnóstico da doença de Chagas crônica, a realização de dois testes sorológicos de princípios metodológicos diferentes, entre ELISA, IFI ou HAI, considerando confirmada a amostra com dois resultados reagentes; em caso de resultados discordantes (inconclusivos), deve-se repetir os testes e, persistindo a discordância, realizar um teste mais específico, como Western Blotting ou PCR.

Em relação ao preconizado para a triagem entre doadores de sangue no Brasil, a partir de 200224 foi instituída a realização de apenas um teste imunoenzimático (ELISA) de alta sensibilidade. Todas as marcas de ELISA utilizadas pelo HEMOPI no período do estudo apresentaram 100\% de sensibilidade e > 99\% de especificidade em testes de validação, realizados entre 500 amostras conhecidas, antes da sua introdução na rotina, e diariamente sua reatividade é verificada na testagem de controles internos positivos e negativos, em paralelo à rotina.

$\mathrm{Na}$ triagem de doadores de sangue privilegia-se a sensibilidade em detrimento da especificidade, tendo em vista a segurança do receptor de transfusão (não se pode admitir resultados falso-negativos). Embora a especificidade descrita em bula das marcas de ELISA utilizadas pelo HEMOPI no período não fossem baixas (de 97,3 a 100\%, segundo os fabricantes), 84,4\% das amostras reagentes na triagem e encaminhadas para testes complementares não se mostraram reagentes nestes últimos. Essa proporção de casos inconclusivos foi tão alta quanto à que se referiu Yasuda 25, no relatório final da XV Reunião Anual de Pesquisa Aplicada em Doença de Chagas (85-90\%), em 1999. Contudo, Araújo et al. 12 encontraram 51\% entre doadores de Pelotas (Rio Grande do Sul); Sabino et al. 16, 65\% entre doadores de São Paulo (Fundação Pró-Sangue), Belo Horizonte (HEMOMINAS) e Pernambuco (HEMOPE). Outros estudos desenvolvidos evidenciaram índices de reações indeterminadas e/ou discrepantes que variaram de 52\% a 69,6\% dos inaptos sorológicos na triagem 15,26,27,28. Nos Estados Unidos, diante de um índice de inaptidão sorológica de 0,012\%, entre 3,5 milhões de doadores, no ano de 2007, 74\% das amostras reagentes não foram confirmadas pela técnica da radioimunoprecipitação (RIPA) 29.

As variações anuais e o alto percentual de casos inconclusivos na investigação dos doadores podem ter ocorrido por diversos fatores. Entre as possíveis causas estão a reatividade cruzada com outros parasitas, como Trypanosoma rangeli e Leishmania sp. 16,30,31, com autoanticorpos encontrados em doenças autoimunes, ou por conta de fatores interferentes responsáveis por reações inespecíficas, como a contaminação cruzada entre amostras e amostras inadequadas (hemolisadas, hiperlipêmicas, armazenadas em temperatura inadequada, com contaminação bacteriana) 8 .

A reatividade cruzada com Leishmania sp. deve ser a principal preocupação, tendo em vista sua alta prevalência no Piauí, em especial na cidade de Teresina. Segundo Drumond \& Costa 32, de 1999 a 2009, 2.498 casos de leishmaniose visceral foram confirmados no Piauí, com prevalência de 7,7 casos/100 mil habitantes no estado e de 16,34 casos/100 mil habitantes em Teresina. No presente trabalho, enquanto a proporção de casos inconclusivos foi de $89,5 \%$ entre doadores residentes em Teresina, entre doadores residentes no interior do estado foi de $69 \%$, reforçando a hipótese de que doadores inconclusivos para doença de Chagas, em especial os residentes em Teresina, podem ser indivíduos com anticorpos anti-Leishmania sp.

Quanto à distribuição do percentual de casos confirmados por RS, os resultados corroboram os achados de estudos anteriores no Piauí, em que as maiores prevalências da doença de Chagas foram descritas em regiões do semiárido (RS de São Raimundo Nonato, Oeiras e Picos) e dos cerrados (RS de Bom Jesus e Floriano) 3 , onde também predomina o T. brasiliensis ${ }^{4}$. Em relação às RS de Valença e de Teresina, que apresentaram maior prevalência de sorologia reagente para doença de Chagas no estudo atual entre doadores, em comparação ao inquérito sorológico realizado no estado em 2002 , observa-se alto percentual de casos confirmados (40,01-100\%) na RS de Valença e baixa confirmação (10,01-20\%) na RS de Teresina. A maior prevalência nessas regiões, e em especial na RS de Valença, chama a atenção para a possibilidade de ter ocorrido aumento da transmissão vetorial nessas localidades entre 2002 e 2013. Vale lembrar que nossos resultados evidenciaram maior prevalência nos municípios com menor taxa de urbanização, e que a segunda maior prevalência foi identificada nos indivíduos que nasceram após 1991. 
Em conclusão, sugere-se que o serviço de hemoterapia estabeleça ou mantenha um fluxo adequado das informações às equipes de vigilância, e que por sua vez, as vigilâncias sanitária e epidemiológica atuem no aprofundamento da investigação dos casos, na identificação das formas de contágio e dos focos de vetores, para o adequado controle desse agravo.

\section{Colaboradores}

Todos os autores contribuíram para o delineamento do estudo, análise, interpretação dos dados e redação final do artigo.

\section{Referências}

1. Dias JCP, Machado EMM, Fernandes AL, Vinhaes MC. Esboço geral e perspectivas da doença de Chagas no Nordete do Brasil. Cad Saúde Pública 2000; 16 Suppl 2:13-34.

2. Martins-Melo FR, Lima MS, Alencar CH, Ramos AN, Heukelbach J. Epidemiological patterns of mortality due to visceral leishmaniasis and HIV/AIDS co-infection in Brazil, 2000-2011. Trans R Soc Trop Med Hyg 2014; 108:338-47.

3. Borges-Pereira J, Castro JAF, Silva AG, Zauza PL, Bulhões TP, Gonçalves ME, et al. Soroprevalência da infecção chagásica no Estado do Piauí, 2002. Rev Soc Bras Med Trop 2006; 39:530-9.

4. Gurgel-Gonçalves R, Pereira FCA, Lima IP, Cavalcante RR. Distribuição geográfica, infestação domiciliar e infecção natural de triatomíneos (Hemiptera: Reduviidae) no Estado do Piauí, Brasil, 2008. Rev Pan-Amazônica Saúde 2010; 1:57-64.

5. Dias JCP. Clínica e terapêutica da doença de Chagas: uma abordagem prática para o clínico geral. Rio de Janeiro: Editora Fiocruz; 1997. 
6. Santana MP. Estudo da soropositividade para Trypanosoma cruzi entre doadores de sangue no Estado do Piauí, Brasil, no período de 2004 a 2013 [Dissertação de Mestrado]. Rio de Janeiro: Escola Nacional de Saúde Pública Sergio Arouca, Fundação Oswaldo Cruz; 2015.

7. Ministério da Saúde. Portaria no 158, de 04 de fevereiro de 2016. Diário Oficial da União 2016; 5 fev.

8. Agência Nacional de Vigilância Sanitária. Manual técnico para investigação da transmissão de doenças pelo sangue. Brasília: Editora MS; 2004.

9. Sobreira ACM, Gomes FVBAF, Silva MAM, Oliveira MF. Prevalência de infecção chagásica em doadores de sangue do Hemocentro Regional de Iguatu, CE. Rev Soc Bras Med Trop 2001; 34:193-6.

10. Soussumi L. Estudo da distribuição de doadores reativos para a doença de Chagas no Hemocentro de Ribeirão Preto, SP [Dissertação de Mestrado]. Ribeirão Preto: Faculdade de Medicina de Ribeirão Preto, Universidade de São Paulo; 2003.

11. Ferreira Filho JCR, Costa PI, Buainain A, Rosa JA. Soropositividade para doença de Chagas entre doadores de sangue em Araraquara, Estado de São Paulo, no período de 2004 a 2008. Rev Soc Bras Med Trop 2011; 44:110-2.

12. Araújo AB, Vianna EES, Berne MEA. Anti-Trypanosoma cruzi antibody detection in blood donors in the Southern Brazil. Braz J Infect Dis 2008; $12: 480-2$.

13. Lima LM, Alves NP, Barbosa VF, Pimenta GA, Moraes-Souza H, Martins PRJ. Prevalence of Chagas disease in blood donors at the Uberaba Regional Blood Center, Brazil, from 1995 to 2009. Rev Soc Bras Med Trop 2012; 45:723-6.

14. Silva VLC, Luna EJA. Prevalência de infecção pelo T. cruzi em doadores de sangue nos hemocentros coordenadores do Brasil em 2007. Epidemiol Serv Saúde 2013; 22:103-10.

15. Ferreira-Silva MM, Pereira GA, Lages-Silva E, Moraes-Souza H. Socioepidemiological screening of serologically ineligible blood donors due to Chagas disease for the definition of inconclusive cases. Mem Inst Oswaldo Cruz 2010; 105:800-5.

16. Sabino EC, Salles NA, Sarr M, Barreto AM, Oikawa M, Oliveira CD, et al. Enhanced classification of Chagas serologic results and epidemiologic characteristics of seropositive donors at three large blood centers in Brazil. Transfusion 2010; 50:2628-37.

17. Agência Nacional de Vigilância Sanitária. Relatório dos dados da produção hemoterápica brasileira - Hemoprod 2013. Brasília: Agência Nacional de Vigilância Sanitária; 2015.

18. Camargo ME, Silva GR, Castilho EA, Silveira AC. Inquérito sorológico da prevalência de infecção chagásica no Brasil, 1975/1980. Rev Inst Med Trop São Paulo 1984; 26:192-204.

19. de Andrade AL, Zicker F, de Oliveira RM, Almeida Silva S, Luquetti A, Travassos LR, et al. Randomised trial of efficacy of benznidazole in treatment of early Trypanosoma cruzi infection. Lancet 1996; 348:1407-13.

20. Sabino EC, Lee T-H, Montalvo L, Nguyen ML, Leiby DA, Carrick DM, et al. Antibody levels correlate with detection of Trypanosoma cruzi DNA by sensitive polymerase chain reaction assays in seropositive blood donors and possible resolution of infection over time. Transfusion 2013; 53:1257-65.

21. Viotti R, Vigliano C, Lococo B, Bertocchi G, Petti M, Alvarez MG, et al. Long-term cardiac outcomes of treating chronic Chagas disease with benznidazole versus no treatment: a nonrandomized trial. Ann Intern Med 2006; 144:724-34.

22. Ministério da Saúde. Portaria no 1.353 , de 13 de junho de 2011. Diário Oficial da União 2011; 14 jun.

23. Secretaria de Vigilância em Saúde, Ministério da Saúde. Consenso brasileiro em doença de Chagas. Rev Soc Bras Med Trop 2005; 38 Suppl 3:7-29.

24. Agência Nacional de Vigilância Sanitária. Resolução no 343, de 13 de dezembro de 2002. Diário Oficial da União 2003; 17 jan.

25. Yasuda MAS. Relatório final da XV Reunião Anual de Pesquisa Aplicada em Doença de Chagas e da III Reunião Anual de Pesquisa Aplicada em Leishmanioses. Rev Soc Bras Med Trop 2000; 33:111-24.

26. Salles NA, Sabino EC, Cliquet MG, Eluf-Neto J, Mayer A, Almeida-Neto C, et al. Risk of exposure to Chagas' disease among seroreactive Brazilian blood donors. Transfusion 1996; 36:969-73

27. Melo AS, Lorena VMB, Moraes AB, Pinto MBA, Leão SC, Soares AKA, et al. Prevalência de infecção chagásica em doadores de sangue no estado de Pernambuco, Brasil. Rev Bras Hematol Hemoter 2009; 31:69-73.

28. Moraes-Souza H, Martins PRJ, Pereira GA, Ferreira-Silva MM, Abud MB. Serological profile concerning Chagas' disease of blood donors at Uberaba Blood Center. Rev Bras Hematol Hemoter 2006; 28:110-4.

29. Moraes-Souza H, Ferreira-Silva MM. Control of transfusional transmission. Rev Soc Bras Med Trop 2011; 44:64-7.

30. Repolês LC. Avaliação do método confirmatório FC-TRIPLEX-IgG1 no esclarecimento diagnóstico e na monitoração sorológica para doença de Chagas em bancos de sangue [Dissertação de Mestrado]. Belo Horizonte: Centro de Pesquisa René Rachou, Fundação Oswaldo Cruz; 2014.

31. Caballero ZC, Sousa OE, Marques WP, SaezAlquezar A, Umezawa ES. Evaluation of serological tests to identify Trypanosoma cruzi infection in humans and determine cross-reactivity with Trypanosoma rangeli and Leishmania spp. Clin Vaccine Immunol 2007; 14:1045-9.

32. Drumond KO, Costa FAL. Forty years of visceral leishmaniasis in the State of Piaui: a review. Rev Inst Med Trop São Paulo 2011; 53:311. 


\section{Abstract}

Despite the decline in prevalence of Chagas disease in Brazil, the Northeast region of the country has favorable conditions for its resurgence. The study aimed to analyze positive Chagas disease serology rates among blood donors in Piaui State from 2004 to 2013. Prevalence of positive Chagas disease serology in blood donor screening was $1 \%$, ranging from $0.4 \%$ in the Uruçui Regional Health District to $2.4 \%$ in the São Raimundo Nonato Regional Health District. Of the state's $220 \mathrm{mu}$ nicipalities, $58.6 \%$ reported cases. Only 34.5\% of the positive samples in screening were referred for complementary tests, and $84.4 \%$ of these showed negative results. Our findings suggest the possibility of persistent vector-borne transmission in areas of Piaui State and the need for measures to improve complementary testing in positive cases detected by screening.

Blood Donors; Donor Selection; Chagas Disease

\section{Resumen}

A pesar del declive en la prevalencia de la enfermedad de Chagas en Brasil, la Región Nordeste presenta condiciones propicias para su recrudecimiento. El objetivo de este estudio fue analizar la positividad por enfermedad de Chagas entre donadores de sangre de Piauí entre 2004 y 2013. La prevalencia de la serología reactiva para la enfermedad de Chagas en la clasificación de donadores fue de un 1\%, variando de 0,4\% en la Regional de Salud de Uruçui, a 2,4\% en la Regional de Salud de São Raimundo Nonato. De los 220 municipios, un $58,6 \%$ presentaron casos. Sólo un $34,5 \%$ de las muestras positivas en la clasificación fueron dirigidas a test complementarios y entre estos, un $84,4 \%$ presentaron resultados negativos. Nuestros resultados indican la posibilidad del mantenimiento de la transmisión vectorial en áreas del Estado de Piauí y la necesidad de la implantación de acciones que mejoren el indice de realización de los test complementarios referentes a los casos positivos en la clasificación.

Donantes de Sangre; Selección de Donante;

Enfermedad de Chagas
Recebido em 14/Jul/2016

Versão final reapresentada em 02/Jun/2017

Aprovado em 27/Jun/2017 